\title{
Continuidad e impronta púnica en la necrópolis de Gades. Evidencias monetales.
}

\author{
Alicia ARÉVALO GONZÁLEZ ${ }^{1}$ \\ Universidad de Cádiz
}

\section{Resumen}

El estudio de las monedas procedentes de las necrópolis de Cádiz de época tardo-púnica y romana ofrece bastantes singularidades y enriquece el conocimiento del peso específico de la tradición local. Ello permite, una vez más, defender la continuidad cultural púnica en el ámbito funerario de Gades hasta al menos mediados del siglo I d.C. Un componente que tanto ha dado que hablar en los últimos años, pero que no se había abordado específicamente desde la óptica numismática.

Palabras clave: Moneda, Necrópolis, Púnico, Romano, Cádiz.

\section{Summary}

The study of the coins proceeding from the necropolis of Cadiz of Punic and Roman period it offers enough singularities and enriches the knowledge of the specific weight of the local tradition. It allows to defend, once again, the cultural Punic continuity in Gades's funeral area up to at least middle of the 1st century A.D., a component that so much exists provided that to speak in the last years, but that had not been approached specifically from the numismatical optics.

Keywords: Coins, Necropolis, Punic, Roman, Cádiz.

\section{INTRODUCCIÓN}

La fuerte impronta púnica en la ciudad de Gades ha contado desde siempre con una amplia justificación histórica, pero son en buena medida los indicios arqueológicos los que pueden permitir perfilar y caracterizar la importancia de este sustrato. No cabe duda que a ello puede contribuir de forma decisiva la información proporcionada por su necrópolis, pues no se puede olvidar que, como Bendala ha señalado en numerosas ocasio-

1 Este trabajo se ha realizado en el marco del proyecto de investigación "Moneda para el más allá. Estudio diacrónico del uso y significado de la moneda en las necrópolis de Gadir, Malaca y Ebusus", financiado por el Plan Nacional nes, las necrópolis son laboratorios privilegiados donde descubrir los aspectos más profundos $\mathrm{y}$ complejos de las sociedades.

Por desgracia el conocimiento científico que tenemos de ellas sigue siendo escaso, ya que la milenaria ciudad de Cádiz cuenta con una serie de elementos de su pasado necesitados aún de un profundo análisis histórico-arqueológico, siendo uno de ellos el de sus necrópolis, máxime si tenemos en cuenta la densidad de sus hallazgos y su

de Investigación Científica, Desarrollo e Innovación Tecnológica del Ministerio de Ciencia e Innovación (Ref. HAR2010-16793). 
complejidad, puesta de manifiesto en las innumerables intervenciones arqueológicas practicadas en las áreas funerarias gaditanas desde hace más de un siglo.

Evidentemente la solución no es otra que la de dotar de un proyecto de investigación sistemático de la ciudad entendida como yacimiento único, que ha sido demandado en más de una ocasión por nosotros mismos y por diversos investigadores (Vallejo y Niveau, 1999: 349; Ruiz Gil, 2006: 42; Vaquerizo, 2010a: 142-170; 2010b: 341-385), $\mathrm{y}$ al que el propio Bendala animaba y alentaba en su artículo al Diario de Cádiz de 30 de mayo de 2004 titulado "Cádiz, ayer y hoy. Un reto arqueológico". Un logro que por el momento no se ha producido, a pesar de que en los últimos años se están dando algunos avances significativos, en gran parte derivados de la implicación directa de varios profesores de la Universidad de Cádiz con la arqueología de la ciudad.

Esta consideración nos llevó hace unos años a iniciar un Proyecto de Investigación sobre las necrópolis de Gadir/Gades, cuyos primeros resultados estamos dando a conocer en diversos foros. Y que mejor lugar y ocasión para presentar una nueva aportación de esta investigación que este homenaje al Profesor Manuel Bendala, de origen y de sentimiento gaditano, quién además ha dedicado una gran parte de su investigación a las necrópolis hispanas, por lo que en numerosas ocasiones hace referencia a las de Cádiz, consciente de la interesante información que proporcionaban las numerosas excavaciones arqueológicas, pero también por su constante preocupación por la arqueología de su ciudad.

\section{DE LA NECRÓPOLIS TARDO- PÚNICA DE GADIR A LA NECRÓPOLIS DE GADES. LA APORTACIÓN MONETAL}

La fase tardo-púnica de esta necrópolis ha sido objeto de una mayor atención en los últimos años, aunque se hace necesaria aún una intensa labor de ordenamiento y clasificación de la documentación y de los materiales. Nosotros mismos nos hemos acercado a ella a través del estudio de las monedas, al ser un material que con relativa frecuencia aparecen en la necrópolis gaditana y del que prácticamente no se conocía nada, al margen de lo que eran los tipos de numerario que sí habían sido publicados por Blanco (1988 a y b).
En efecto esta investigación nos ha permitido conocer que la participación de la moneda en el mundo funerario gaditano se produce a partir de la fase tardo-púnica y con las primeras amonedaciones realizadas por la ciudad de Gadir, tanto en las propias tumbas como en conexión con el conjunto de estructuras -pozos, piletas, fosas rellenas de materiales, pequeños espacios de culto- que espacial y funcionalmente se encuentran relacionadas con la necrópolis y con la liturgia desarrolla en torno al mundo funerario de esta época (Arévalo, 2010b: 15-36).

Las deposiciones monetarias en las tumbas no siempre aparecen de la misma forma, por lo que parece evidente que no pueden responder a un mismo significado, como hemos analizado recientemente en algunos trabajos (Arévalo, 2010a: 507-528; 2010b: 15-36), a los que remitimos para conocer detalladamente los distintos hallazgos y su procedencia. Así, en ocasiones las encontramos junto al resto de los elementos que forman parte del ajuar funerario, junto a materiales diversos - ungüentarios, cerámica, piezas de orfebrería-; quizás esta incorporación se deba a que son objetos muy apropiados dado su notable significado simbólico, al contener imágenes y símbolos religiosos que debían de complacer a los dioses, y su poco valor material, que permitía que estuvieran al alcance de la mayoría de la población. También podía obedecer a que por su valor como instrumento de pago podía facilitar la vida del difunto en el más allá, al mismo tiempo que podría simbolizar las posesiones materiales del difunto que viajaban de este modo con él (Cantilena, 1995:165-177). Esta variedad de significados parece encajar bastante bien con el hecho de encontrar unas veces un solo ejemplar y en otras ocasiones un conjunto de piezas, como el lote formado por 37 monedas de Gadir de la serie VI y el denario romano-republicano de la familia Fonteia (RRC 353/1b) recuperado en la urna cineraria del enterramiento $\mathrm{n}^{\circ} 51$ calle García Carrera $n^{\circ} 9$ (Blanco, 2009: 217-244). El conjunto monetal se encontró en el interior de una caja de pequeñas dimensiones de hueso chapeada en plata y claveteada con tachuelas de bronce, que acompañaba, junto con otros elementos materiales, a los escasos restos óseos de una mujer joven. Es evidente que la heterogeneidad de objetos que forman parte de los ajuares, de los que hace falta un estudio exhaustivo, impide por el momento abordar correctamente la cuestión del significado de la moneda dentro de ellos. 
En otros casos las monedas aparecen dispuestas sobre una determinada parte del cuerpo del cadáver, unas veces con sentido de viático o como elemento apotropaico, y en otras más claramente como amuleto, de ahí el elevado número de piezas de Gadir que presentan perforación (Alfaro, 1993: 261-276). Sin embargo, aunque queda por clarificar el por qué de la disposición en distintas partes del cuerpo del cadáver, lo que parece no estar presente es el rito del "óbolo de Caronte", pues no se han encontrado monedas en la boca del difunto.

Otra de las principales novedades ha sido documentar que el numerario no sólo está presente en los enterramientos, sino que también aparece con cierta frecuencia entre los materiales recuperados en el conjunto de estructuras que espacial y funcionalmente se encuentran relacionadas con la necrópolis y con la liturgia desarrollada en torno al mundo funerario a partir también de la fase tardo-púnica (Arévalo, 2006: 75-98). Es cierto que éstas no siempre aparecen, aunque contamos con al menos un hallazgo en cada una de las diferentes estructuras descritas, e igual que en las tumbas se trata mayoritariamente de moneda de Gadir, siendo más habitual su presencia en los pozos que en el resto de las estructuras, a veces formando parte de depósitos rituales, pero también como resultado de las limpiezas cíclicas de la necrópolis (Arévalo, 2009: 197-206). Además, al igual que en las tumbas, se encuentran piezas aisladas o conjuntos monetales, como el interesante hallazgo de trece mitades de Gadir de la serie III.2 recuperado en los niveles inferiores de la fosa excavada en los Cuarteles de Varela, en el denominado Nivel IIIb, que por los materiales documentados, se ha datado en momentos de finales del siglo III a.C., y que se encontraba sellado, a techo, por niveles de cronología republicana (López Ruiz y Ruiz Tinoco, 2011). Un hallazgo que ha sido interpretado como una ocultación apresurada, de piezas de bajo valor, ante un momento de especial agitación, quizás debido a la llegada de las tropas romanas a las puertas de Gadir, que empujó al propietario a deshacerse de estas monedas ante el riesgo de perderlas. Sin embargo, pensamos que se hace necesario conocer el resto de los materiales que aparecieron en la fosa, para clarificar el significado de este interesante conjunto. Ya que a tenor de la variabilidad de hallazgos documentados podría plantearse que la moneda de Gadir podría haber desempeñado distintas funciones en el desarrollo de algunos de los rituales funerarios -ofrendas, libaciones, abluciones, banquetes- cuestiones que en los próximos años convendrá ir clarificando y perfilando.

\section{ANTIGUAS Y NUEVAS EVIDENCIAS DE LA HERENCIA PÚNICA EN EL ÁMBITO FUNERARIO DE GADES}

La entrada de Gades en la órbita romana no implicó una completa desaparición del substrato local, cuyas huellas permanecen, es más lo normal es comprobar cierta continuidad, que a veces hace difícil incluso reconocer la filiación cultural de algunos enterramientos, como ha señalado Morales (2006: 39).

Aunque las evidencias de la impronta púnica son muchas y muy variadas pues afectan a ritos, ajuares, tipologías funerarias, que son las que suelen señalarse, hace falta un estudio específico y detallado de las mismas; así como incorporar nuevas informaciones como las aportadas por la numismática, de lo que trataremos a continuación. Si bien antes recordaremos algunas de las otras manifestaciones de tradición púnica más enarboladas hasta ahora al analizar la necrópolis romana (Vaquerizo, 2010a y 2010b).

En efecto, una de estas manifestaciones es el uso habitual de cipos y estelas como señalización funeraria, habitual en el mundo púnico, y que en la necrópolis de Gades se caracterizan por estar realizadas ambas con la característica biocalcarenita local, conocida habitualmente como piedra ostionera, además de estucadas y con un rebaje en la parte superior para el titulus sepulcrales, grabada sobre una placa de mármol y después encastrada en el soporte de piedra (López de la Orden, 1997: 256; 2001: 45 y 50).

Destaca asimismo entre los tipos arquitectónicos, la predilección por las cámaras funerarias de carácter familiar o colectivo y parcialmente hipogeícas, tan habitual en la tradición funeraria púnica que perdura en la etapa romana, y que servían para acoger enterramientos en loculi, los denominados "columbarios" en la historiografía local (fig. 1). Por el contrario, están ausentes los monumentos funerarios de filiación itálica tan característicos en otras ciudades de la Bética (Vaquerizo, 2001: 131-160; Ruiz Osuna, 2007 y 2010). También algunos tipos de urna empleadas para guardar los restos óseos incinerados son suma- 


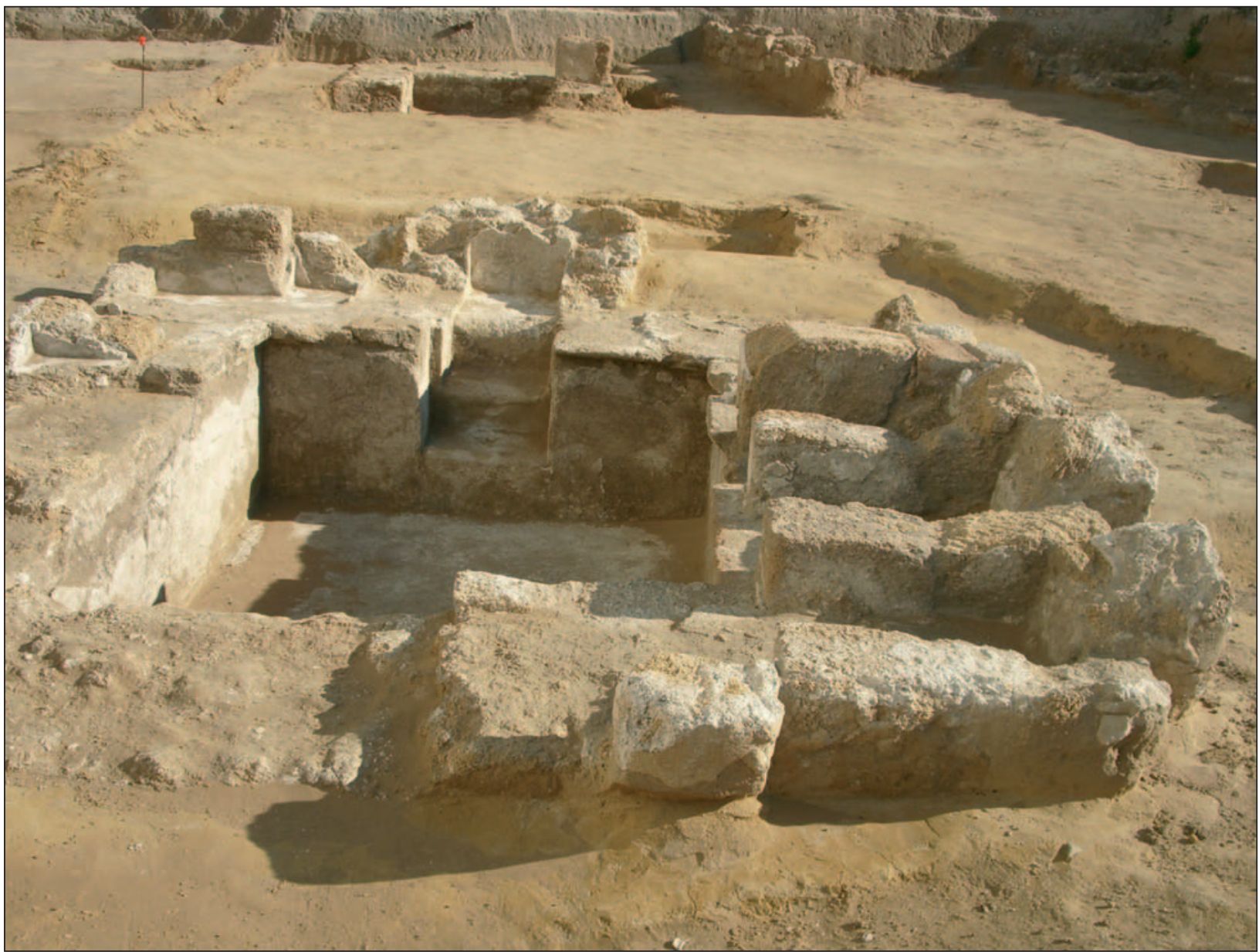

Figura 1. Columbario $\mathrm{n}^{\circ} 1$ excavado en el solar de la Ciudad de la Justicia (fotografía cortesía de F.J. Blanco).

mente indicativos de cuanto venimos diciendo, como sucede con las urnas de cerámica decoradas con bandas pintadas, cuyo uso está constatado desde el siglo VI a.C. hasta el siglo I d.C., según un reciente estudio de López Rosendo (2010: 145-177). Quien, además, apunta que quizás a ello se deba también la destacada preferencia por la utilización, en la fase romana de la necrópolis de Cádiz, de urnas de cerámica frente a las de otro tipo, como las de vidrio o plomo, siendo una evidencia más de esta tradición púnico-gaditana.

Igualmente frecuente fue la pervivencia de las inhumaciones en fosa simple excavadas en la arcilla, un tipo de enterramiento constado en la necrópolis gaditana de la fase fenico-púnica, y que perdura hasta bien entrado el siglo I d.C., mostrando el claro arraigo de las costumbres funerarias semitas entre los habitantes de Gades.

Otra posible pervivencia de sus tradiciones se puede observar en los ajuares con una escasa presencia de determinadas producciones cerámicas, como la terra sigillata italica, en este sentido recientemente Bustamante (2010: 161 y 168) ha sugerido que su ausencia puede evidenciar una reticencia palpable ante un producto foráneo claramente romano en un contexto de raigambre típicamente feno-púnica. Por el contario, si comparecen en los ajuares las cerámicas del tipo Peñaflor, una producción que, como ha manifestado Bustamante (2008: 196-197), en morfología y en conformación técnica tienen grandes similitudes con los barnices rojo fenicio-púnico gaditano, las también denominadas de tipo Kuass, por lo que esta investigadora opina que se podría considerar más que una imitación inicial de productos itálicos una fase muy tardía de producciones engobadas de tradición hispana.

La ausencia de este tipo de cerámicas en determinadas necrópolis hispanas de clara raigambre púnica fue hace tiempo resaltada por Bendala (1991 y 2002:142) al tratar, entre otras, la necrópolis occidental de Carmona y que podría evidenciar el sustrato púnico de la ciudad. Un aspecto sobre el que convendría profundizar en Cádiz pues sabemos por los estudios monográficos rea- 
lizados recientemente por Niveau de Villadary (2010: 179-250) que una de las particularidades del mundo funerario tardopúnico gaditano es la carencia casi completa de ajuares cerámicos en el interior de las tumbas, mientras que son muy abundantes en las fosas y pozos rituales. Una caracterización y comparación que es necesaria acometer para la época romana de la necrópolis tanto en tumbas como en el resto de las estructuras funerarias.

En este sentido, queremos resaltar que al analizar los hallazgos monetales en los pozos vinculados espacialmente a la necrópolis (Arévalo, 2009: 197-216), pudimos comprobar que en algunos se localizaron ciertas producciones de sigillata, pero no las itálicas. Así en el pozo $\mathrm{n}^{\circ} 4$ documentado en la plaza de Asdrúbal esquina con la c/ Amilcar Barca (Blanco, 1998), denominado en la Memoria de la excavación como pozo de vertido de urnas cinerarias, el primer nivel de relleno estaba formado por sigillata africana A, cerámica africana de cocina, un fragmento de una caja de hueso, trozos de plomo que servirían de protección a las urnas de vidrio, y tres ases pertenecientes a Nerón, Vespasiano y Antonino Pío. Según sus excavadores se trata de un pozo que, aunque su construcción pudo ser anterior a la época romana, se utilizó hasta mediados del s. II d.C. para depositar diversos vertidos pertenecientes a un sector de la necrópolis. De ahí, que interpretáramos su relleno como resultado de las limpiezas cíclicas de la necrópolis.

Otro ejemplo lo encontramos en el pozo 2 de la Avda. Amilcar Barca excavado durante la intervención arqueológica del año 2001 (fig. 2). Según los datos recogidos de la Memoria de excavación (Sibón, 2001), aunque el relleno es de época altomiperial -entre finales del s. I d.C. y primera mitad del s. II d.C.-, parece por la factura y por la aparición de cerámicas campanienses del tipo A en la fosa de cimentación que se construyó en torno a la primera mitad del s. II a.C. En cuanto a los materiales documentados en los distintos niveles de rellenos. El primero está compuesto por sigillatas africanas A, cerámicas comunes, fragmentos de mármoles y fragmentos de inscripciones funerarias; el segundo, que es donde se recogieron las dos monedas, se caracteriza por la abundancia de cenizas de las incineraciones de la necrópolis, los fragmentos de lucernas, sigillatas, abundantes restos de fauna, placas de mármol, tegulae y dos monedas inclasificables por estar sumamente desgastadas. Así mismo, cegando el nivel freático se encontraron gran cantidad de piedras, una inscripción funeraria y una copa de alabastro; por último, en el fondo del pozo se localizo un ánfora del tipo Beltrán IIb de factura local totalmente fragmentada pero completa, que según sus excavadores podría interpretarse como un acto de inauguración del depósito, de ahí que planteen la posibilidad de que más que un vertedero de las limpiezas de la necrópolis, se tratara de depósitos de rituales funerarios de tradición púnica. Aunque es cierto, que es muy llamativa la apertura de la estructura que hace pensar en un acto ritual, pensamos que la composición de los rellenos, sobre todo las cenizas de las incineraciones y las inscripciones funerarias, parecen ser más resultado de las limpiezas cíclicas de la necrópolis (Arévalo, 2009: 197-216).

Estos dos ejemplos sirven para hacer una llamada de atención sobre la presencia de determinadas producciones de sigillata y la ausencia de otras, como las itálicas, en los pozos y también en las tumbas, una cuestión que convendría estudiar de forma sistemática, para profundizar en la caracterización de la pervivencia de la tradición púnica en la necrópolis de Gades. Además, conviene resaltar que cuando aparece la moneda romana imperial en estos pozos, son siempre resultados de limpiezas cíclicas de la necrópolis, mientras que la amonedación de Gadir está también formando parte de depósitos rituales, por lo que podría reflejar un cambio en el uso dado a los pozos en época republicana e imperial.

En este sentido creemos que de nuevo la moneda procedente de contextos funerarios de época romana puede arrojar una rica información, y aunque falta un análisis exhaustivo ya que estamos trabajando sobre el tema en la actualidad, podemos aportar ciertos datos de interés. Ya hemos aludido en el apartado anterior que la incorporación de la moneda en el mundo funerario gaditano no parece remontarse más allá del III a.C., momento en el que la ciudad comienza a contar con su propio numerario y lo incorpora con usos y significados distintos en un significativo número de enterramientos tanto de incineración como de inhumación (Arévalo, 2010 a y b; 2011). Por el momento en el que se empieza a documentar la aparición de estas primeras acuñaciones en las tumbas, nos decantamos por el origen púnico de esta costumbre. Hecho que contrasta con otras necrópolis púnicas de la península, así el hallazgo de numerario en las necrópolis de Carmona (Sevilla) resulta excepcional, es más diversos 


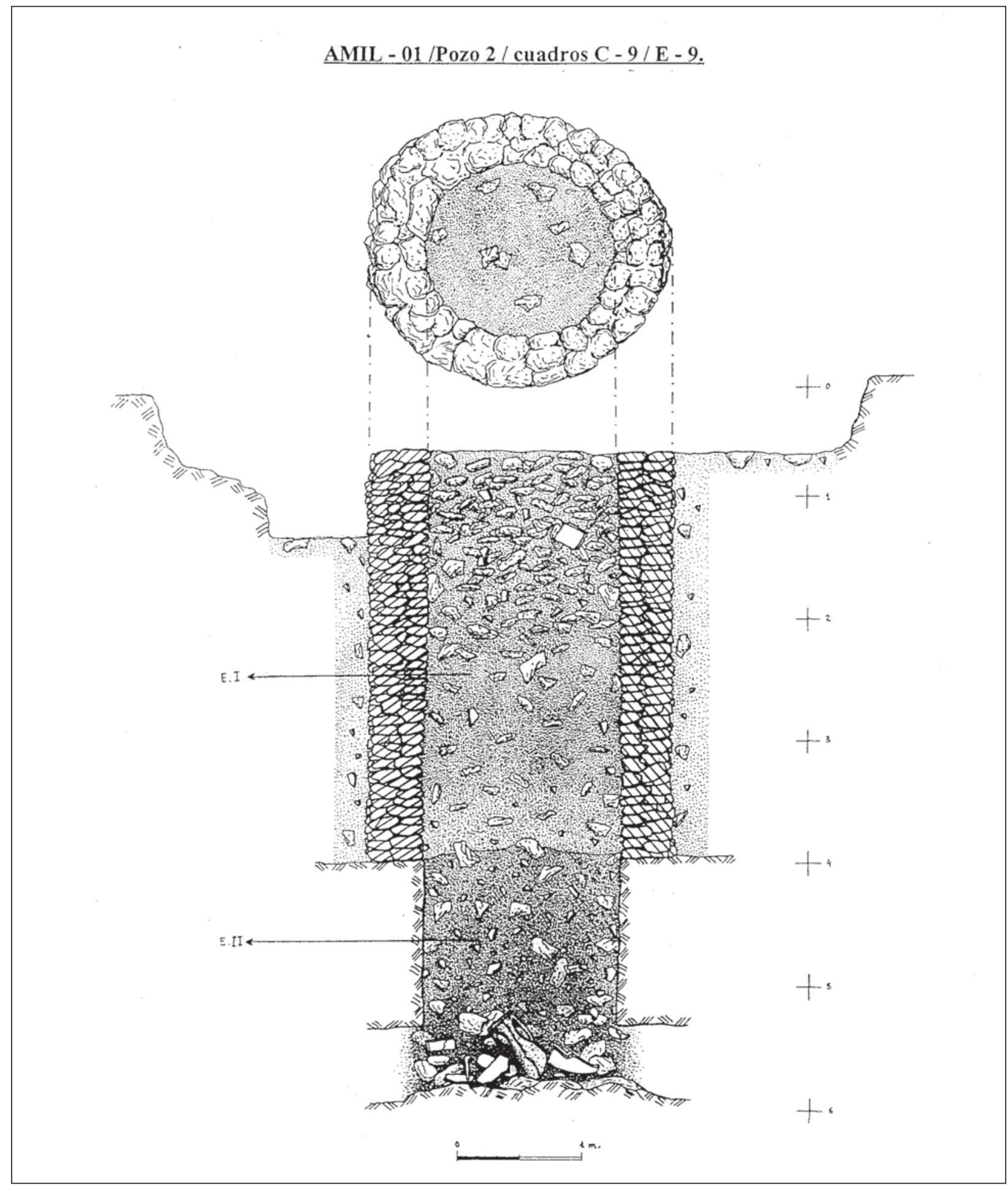

Figura 2. Dibujo del relleno del pozo $\mathrm{n}^{\circ} 2$ de la Avda. de Amílcar Barca (tomado de Niveau de Villedary , 2001: fig. 12).

autores han insistido en la ausencia de hallazgos monetales en algunos sectores de la necrópolis y su presencia en otros como un elemento étnico diferenciador. Así, mientras que en la necrópolis occidental de Carmo no aparecen acuñaciones, sí están presentes en el cementerio septentrional, a partir del siglo II d.C. (Belén et alii, 1986). El propio Bendala (1991a y b, 1995 y 2002) ha planteado que la ausencia generalizada de monedas, junto con otras evidencias rituales, como la ya comentada ausencia de sigillata en los ajuares, y la propia tipología de las tumbas, en la necrópolis romana de Carmona en pleno siglo I d.C. es una muestra "del afloramiento de una personalidad 
colectiva que remitía al sustrato púnico o turdetano/púnico de la ciudad", una sugerente hipótesis que redunda en el valor informativo de la moneda en el ritual funerario y sobre la que habría que profundizar cuando se tanga una mayor información.

En la necrópolis romana de Gades la costumbre de acompañar al difunto con al menos una moneda no sólo se mantiene sino que parece hacerse más habitual hasta avanzada la época imperial, pues el número de hallazgos monetales se multiplica. Pero a partir del siglo III d.C. parece abandonarse esta costumbre, ya que de las 83 monedas recuperadas de los siglos III-V d.C. en la necrópolis de Cádiz, procedentes de catorce intervenciones arqueológicas, ninguna aparece claramente en el interior de la tumba, como ha puesto de manifiesto López Eliso (2009: 537-582), siendo habitual que éstas se encuentren en los alrededores de las sepulturas, en pozos y piletas acompañando a otros materiales y que son fruto de las limpiezas cíclicas del área funeraria, si bien, también se encuentran entre las fosas de saqueo realizadas para el proceso de desmonte de algunas estructuras funerarias con el fin de aprovechar sus elementos constructivos, así como para recuperar los ajuares.

Aunque está aún por sistematizar toda la información proporcionada por las excavaciones arqueológicas practicadas en las distintas áreas de la necrópolis, labor que estamos acometiendo en la actualidad, sabemos por el numerario publicado (Blanco, 1988 a y b) que se han encontrado ejemplares de las siete series de la ciudad (Alfaro, 1988), revelando la amplia continuidad de esta tradición. Además, es la serie sexta (figura 3), que se fecha entre los siglos II-I a.C. las más habitual, siendo esporádica la presencia de numerario foráneo, a pesar del gran número de acuñaciones con las que para estos momentos se cuenta en Hispania, lo que podría ser un signo más de ese rasgo de conservadurismo al que Corzo (1992: 277) se refería como "definitorio de su tradición cultural propia, cerrada a ciertas modas".

Es más, monedas de esta sexta emisión aparecen incluso con acuñaciones de Claudio, como muestra la tumba $n^{\circ} 7$ excavada en la calle Acacias en los años 80 del siglo pasado, según consta en el libro de registro del Museo de Cádiz, pues no hay ninguna publicación sobre esta intervención. Esta misma asociación se constata en la incineración 18 -U.E. 93 de la cuadrícula G-2 del sector NE del solar de la Ciudad de la Justicia, pero de la que desconocemos sus características al no describirse en la Memoria de la intervención arqueológica (Sibón et alii 2007). Incluso este tipo de emisión aparece conjuntamente con numerario de Nerva, como parece que se documentó en la tumba $\mathrm{n}^{\circ} 4$ de la calle General Ricardos $\mathrm{n}^{\circ}$ 5-7 (Perdigones, Gordillo y Blanco, 1988: 59), una intervención que aportó gran cantidad de monedas, pero que fueron publicadas sin su contexto, por lo que en la actualidad lo estamos estudiando, de ahí que todavía no podamos facilitar una mayor información.

A pesar del deficiente análisis contextual, lo que si parece ser frecuente es la aparición conjunta de numerario de Gadir e imperial, fundamentalmente de Claudio, lo que demuestra una continuidad muy marcada del uso funerario de las acu-

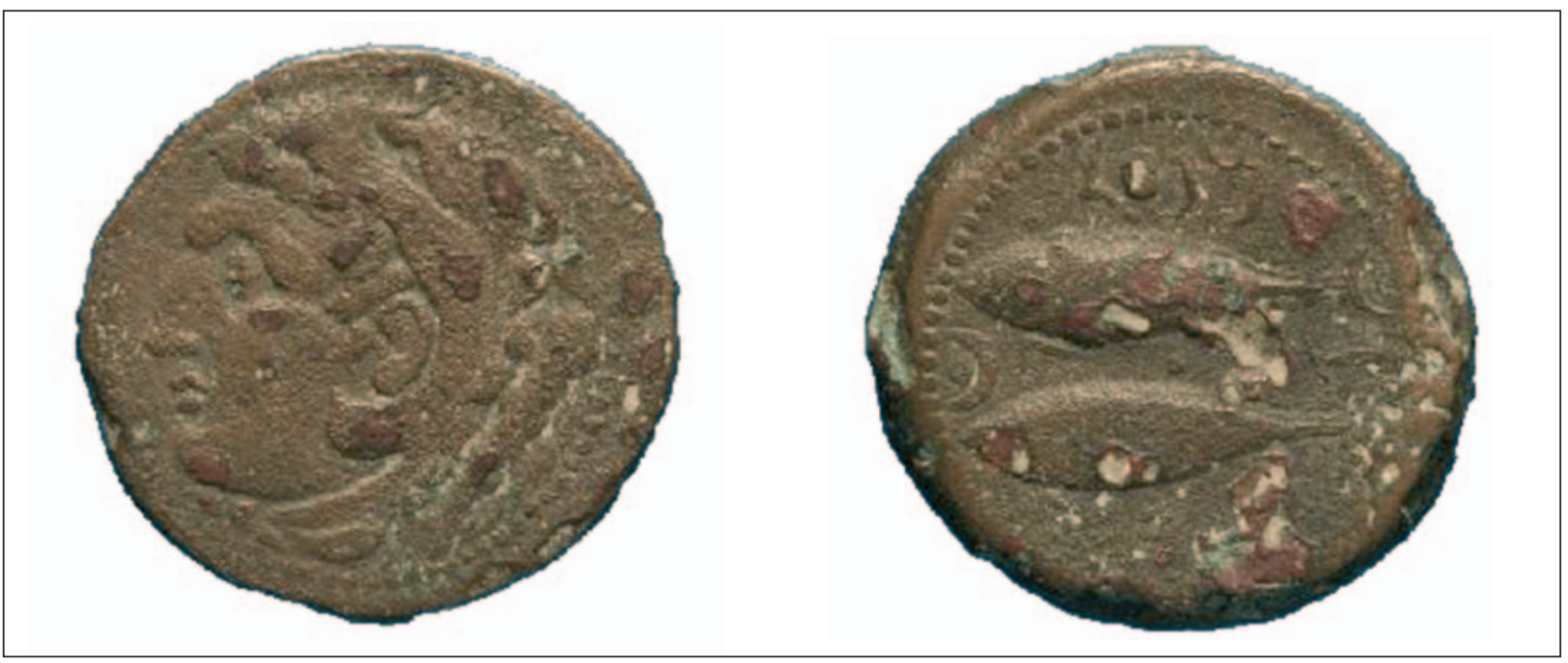

Figura 3 a $y$ b. Unidad de Gadir de la serie VI (MAN). 
ñaciones de la ciudad. No es casualidad que sean precisamente los objetos vinculados a los comportamientos rituales y funerarios, los aspectos más conservadores de una sociedad y los que más tardan en desaparecer o asimilarse a los nuevos; lo que al mismo tiempo nos demuestra una pervivencia de sus antiguas y más profundas creencias.

También creemos que es significativo que a pesar de que durante el reinado de Augusto la producción monetal de Gades, serie VII, es menor a la etapa anterior, sus acuñaciones siguen siendo las más frecuentes en la necrópolis, estando presentes tanto en tumbas de inhumación e incineración como en pozos. Un ejemplo lo tenemos en la pieza documentada en la urna 4 de la excavación practicada en 1999 en el edificio "Puerto Varela" de la Avda. de Andalucía (Miranda y Pineda, 1999: 63). Se trata de una incineración en urna cerámica, con cuenco de forma globular y tapadera, depositada en una fosa excavada en la arena. En su interior se encontraron los huesos calcinados del difunto y lavados, un ungüentario cerámico de perfil fusiforme, del tipo C6 de Muñoz (1987: 520-525), algunos fragmentos cerámicos no identificados y un dupondio de Gades de la serie VII.D.2.

En cuanto a los hallazgos en pozo, creemos que resulta de sumo interés el ejemplar documentado en la zona E de la Plaza de Asdrúbal excavada en los años 1983-1984, pues además de constatar la presencia de numerario gaditano de época augustea, creemos que altera significativamente tanto la interpretación como la datación del relleno del pozo. En efecto, aunque los resultados de esta intervención no han sido publicados y tan sólo se cuenta con referencias indirectas (Muñoz, 1983-84: 50); Niveau (2001: 197-198) lo recoge en su estudio sobre los pozos púnicos y menciona explícitamente "la existencia, cortando la fosa de un grupo de sillería, de un pozo púnico, que se fecha por posición estratigráfica y los materiales que formaban su relleno en el s. III a.C.". Pero como la citada investigadora aclara (Niveau, 2001: 198, nota 51), los datos con los que se cuenta son informaciones verbales, de ahí que no se mencione ningún tipo de material que permitan confirmar la cronología. Sin embargo, entre las monedas procedentes de esta intervención, y según consta en el libro de registro de entrada del Museo de Cádiz, sabemos que se recogieron en el interior de este pozo tres monedas: un cuarto de Seks, un cuarto de Gadir de la serie VI y un dupondio de Gades de la serie VII. La cronología de estas piezas, todas posteriores al siglo III a.C. -siendo la más tardía el dupondio de Gades del 19 a.C.-4 d.C.-, nos llevaron a poner en cautela tanto la datación púnica propuesta para el relleno de este pozo como la interpretación del mismo como un depósito ritual (Arévalo, 2009: 197-216), siendo imprescindible conocer y analizar el resto de los materiales del relleno para poder hacer una correcta interpretación del mismo.

Por otra parte, queremos resaltar que entre las acuñaciones de esta última emisión parece elegirse preferentemente las que continúan mostrando la imagen de su dios tutelar, Melkart (fig. 4), como se constata en los ejemplares recogidos en la Plaza de Asdrúbal (Blanco, 1988a: 535) o en el solar de la calle General Ricardos $\mathrm{n}^{\circ}$ 5-7 (Perdigones, Gordillo, Blanco, 1988: 59), lo que

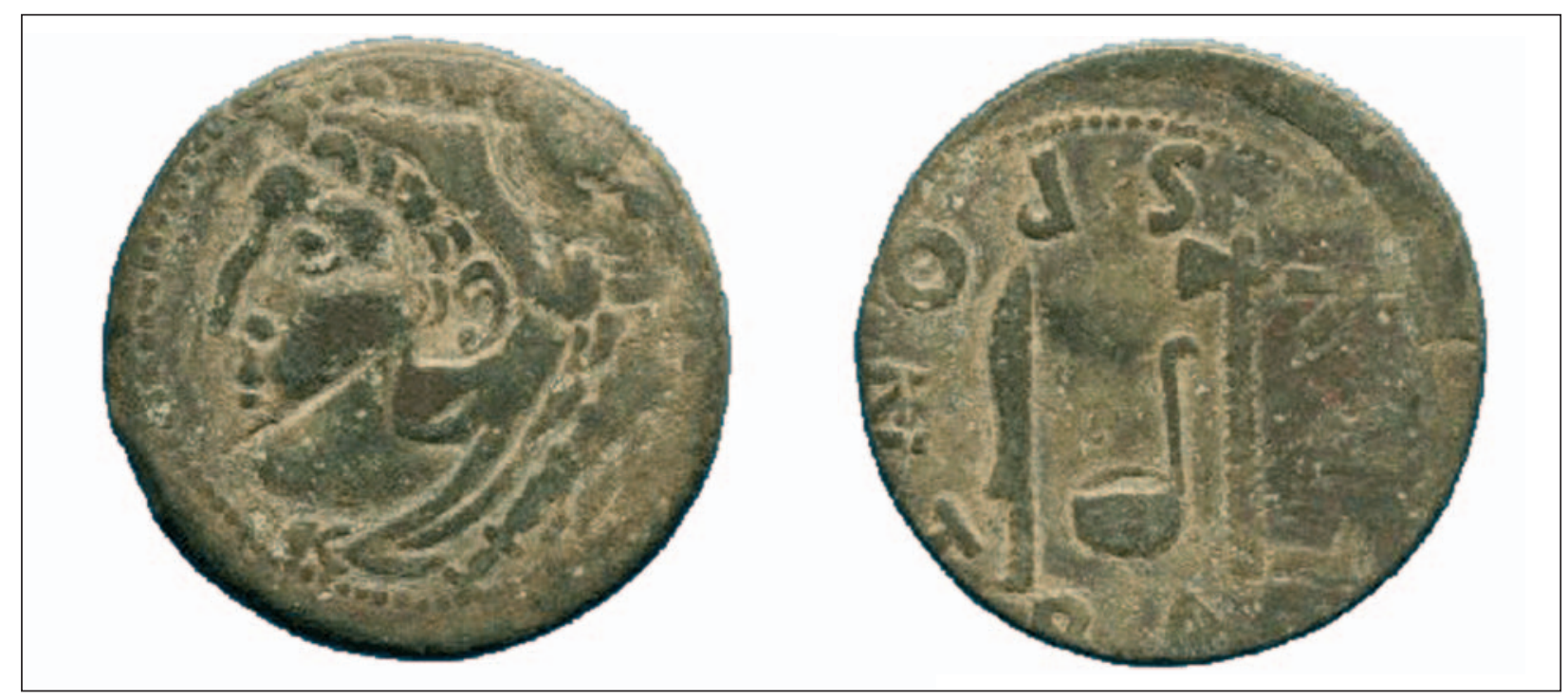

Figura 4 a $y$ b. Unidad de Gades de la serie VII (MAN) 
podría evidenciar una intimidad relación entre el acto de depositar la moneda en la tumba y la imagen que ésta porta.

Es sabido que esta divinidad tuvo suma importancia en todos los aspectos de la vida cotidiana de los ciudadanos de Gadir/Gades, donde ejerció una enorme influencia gracias a sus polivalentes atribuciones protectoras y benefactoras. Omnipresente y ubicuo durante la vida de los gaditanos, es fácil imaginar que este predominio se trasladara también al mundo de los muertos. En realidad, el simbolismo de las cenizas de Melkart era especialmente fuerte en Gades, lugar donde se decía que se guardaban las mismísimas reliquias cremadas y cenicientas de Melkart. Sin duda esta historia, además de proporcionar un noble pasado mítico a la ciudad, impregnaría la concepción escatológica de la ciudad, cuyos sacerdotes, encargados de la realización de los rituales funerarios, perpetuarían y celebrarían.

Parece que Gadir-Gades encuentra en la moneda un práctico medio de expresión para figurar plásticamente a su divinidad, que tradicionalmente no había contado con este tipo de representaciones. Así, el aniconismo semita es superado por la necesidad de acuñar numerario siguiendo los prototipos helenísticos. A partir de este momento, la imagen divina estará al alcance de todos sus fieles y los gaditanos la incluyen en las necrópolis. Este pudo ser uno de los motivos para elegir de entre sus emisiones augusteas, aquellas que continúan representando a su divinidad tutelar, y quizás también sea ésta la razón por la que su anterior emisión, acuñada durante los siglos III a.C., se encuentre habitualmente en los enterramientos de principios del siglo I d.C., tanto solas como junto con numerario de Claudio. Este mismo motivo quizás también podría explicar los escasos hallazgos de numerario de época augustea, tanto provincial como imperial.

Paulatinamente las acuñaciones oficiales romanas van imponiéndose, en un momento que podemos situar en la segunda mitad del siglo I d.C., y al igual que en la fase tardo-púnica éstas se dispone sobre distintas partes del cuerpo. Como muestran diversas inhumaciones del solar gaditano de la Ciudad de la Justicia (Sibón et alii, 2007; Sibón, Gómez y Niveau, 2010: 148-158), donde se han recogido un gran número de monedas que estamos estudiando en la actualidad. Así, un as de Augusto se halló en la pelvis del difunto en la inhumación $\mathrm{n}^{\circ} 11$, ésta consistía en una fosa sim- ple sin cubierta, en cuyo interior se documentaron los restos de un individuo adulto, posiblemente femenino, en posición decúbito supino, con los brazos a los lados del tórax. Dos ases de Claudio se localizaron dispuestos sobre la pelvis de sendos cadáveres en las inhumaciones 29 y 32, la primera es una cista formada por seis tegulae que se encuentran cubiertas por otras cuatro colocadas a dos aguas. En su interior aparecieron los restos de un individuo adulto, de sexo femenino, en posición decúbito supino con la cabeza orientada al norte y los brazos y las piernas extendidas. En cuanto a la tumba 32 es una fosa simple rectangular, con cubierta de tegulae a dos aguas. En su interior se hallaron los restos, bastante mal conservados, de un individuo adulto, de sexo femenino colocado en posición decúbito supino, con los brazos semiflexionados y las piernas extendidas. Asimismo, un as de Claudio de imitación local apareció dispuesto en la cadera del difunto en la inhumación $\mathrm{n}^{\mathrm{o}} 3$, una cista con tegulae en el fondo, en la pared y en la cubierta, pero cubierta con sillares de arenisca de grandes proporciones. El individuo era un adulto, de sexo masculino, en posición decúbito supino con las piernas extendidas. Junto al cadáver aparecieron dos ungüientarios de vidrio y un aplique de metal

Esta costumbre parece que perdura en la necrópolis de Gades al menos hasta finales del siglo II, como constata el as de Antonino Pío documentado en la tumba $n^{\circ} 9$ de esta misma intervención arqueológica. Esta consistía en una cista formada por seis sillares de biocalcarenita colocados verticalmente, que estaban cubiertos por otros seis sillares del mismo tipo de piedra colocado a dos aguas. La cabecera estaba orientada al norte y la zona de los pies se encontraba afectada por una pantalla de hormigón correspondiente a los cimientos de una construcción moderna. En el interior se depositó los restos de un individuo adulto, de sexo masculino, en posición decúbito supino con el brazo derecho flexionado y apoyado sobre la pelvis, mientras que el izquierdo se encontraba extendido, y las piernas extendidas. Como único ajuar llevaba dos cuencos de cerámica común romana y un silex; bajo el cráneo se localizó la moneda.

Conviene destacar que a pesar de tener constatada distintas posiciones de la moneda sobre el cuerpo del difunto, en ningún caso aparece en la boca, lo que podría indicar que ni siquiera en época romana arraiga el mito del "óbolo de Caronte" en Gades ${ }^{2}$; un hecho que contrasta con 
otras necrópolis altoimperiales donde si se documenta esta tradición, como sucede en la Villa de Madrid en Barcelona (Beltrán, 2007: 38) o en la necrópolis de La Misericordia en Valencia (Gozalbes, 1997: 197-212), por citar algunos ejemplos.

También continúa utilizándose la moneda como amuleto como ejemplifica el numerario oficial romano con orificio encontrado en diversas tumbas. Es el caso del as perforado de Claudio de imitación local (fig. 5) documentado en la inhu- mación 5 de la Ciudad de la Justicia en Cádiz (Sibón et alii, 2007, 17). Se trata de una tumba con cubierta de cuatro tegulae a dos aguas muy deterioradas, orientada hacia el norte. Contenía los restos de un individuo infantil, en posición decúbito supino con los brazos semiflexionados a los lados del cuerpo, faltándole la parte inferior de las piernas.

En ocasiones, estas perforaciones se encuentran en la parte central de la pieza (fig. 6), como la documentada en la inhumación $\mathrm{n}^{\mathrm{o}} 10$ de esta

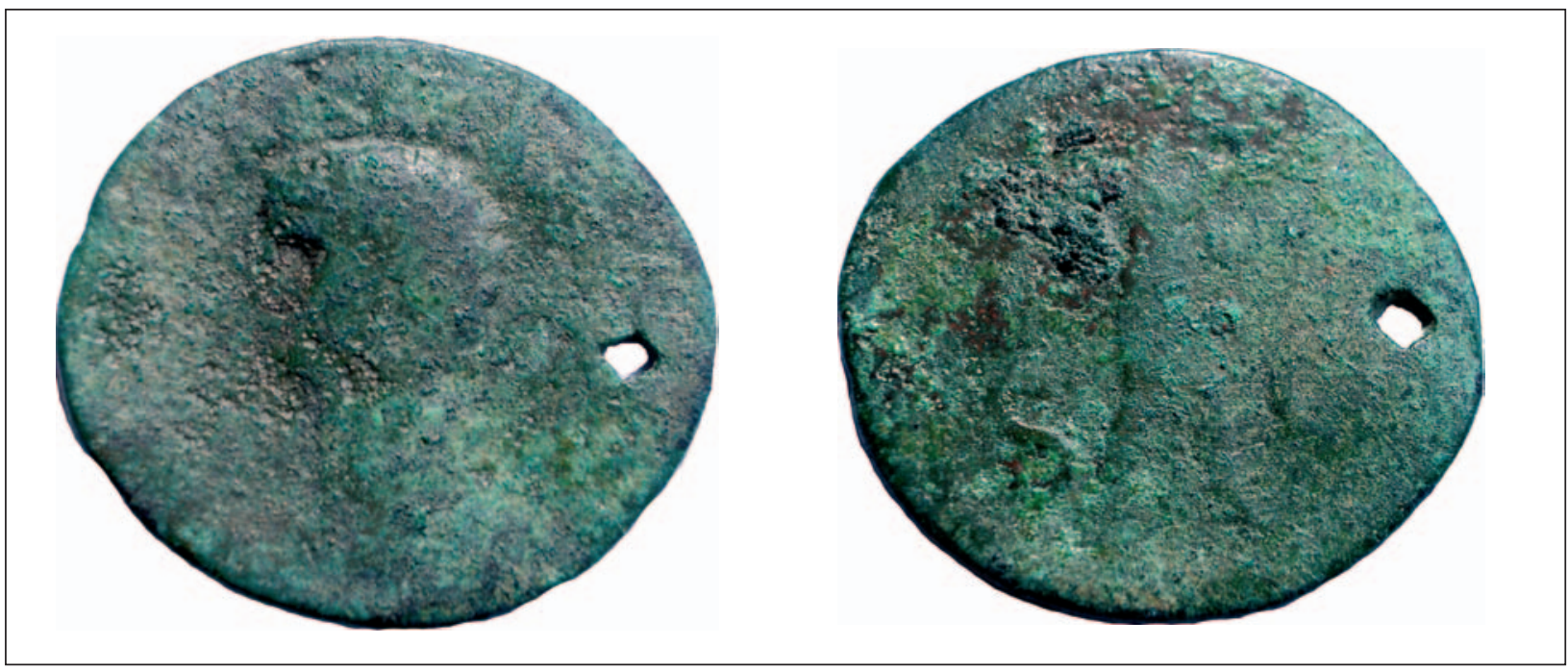

Figura 5. As de Claudio perforado procedente de la Ciudad de la Justicia.

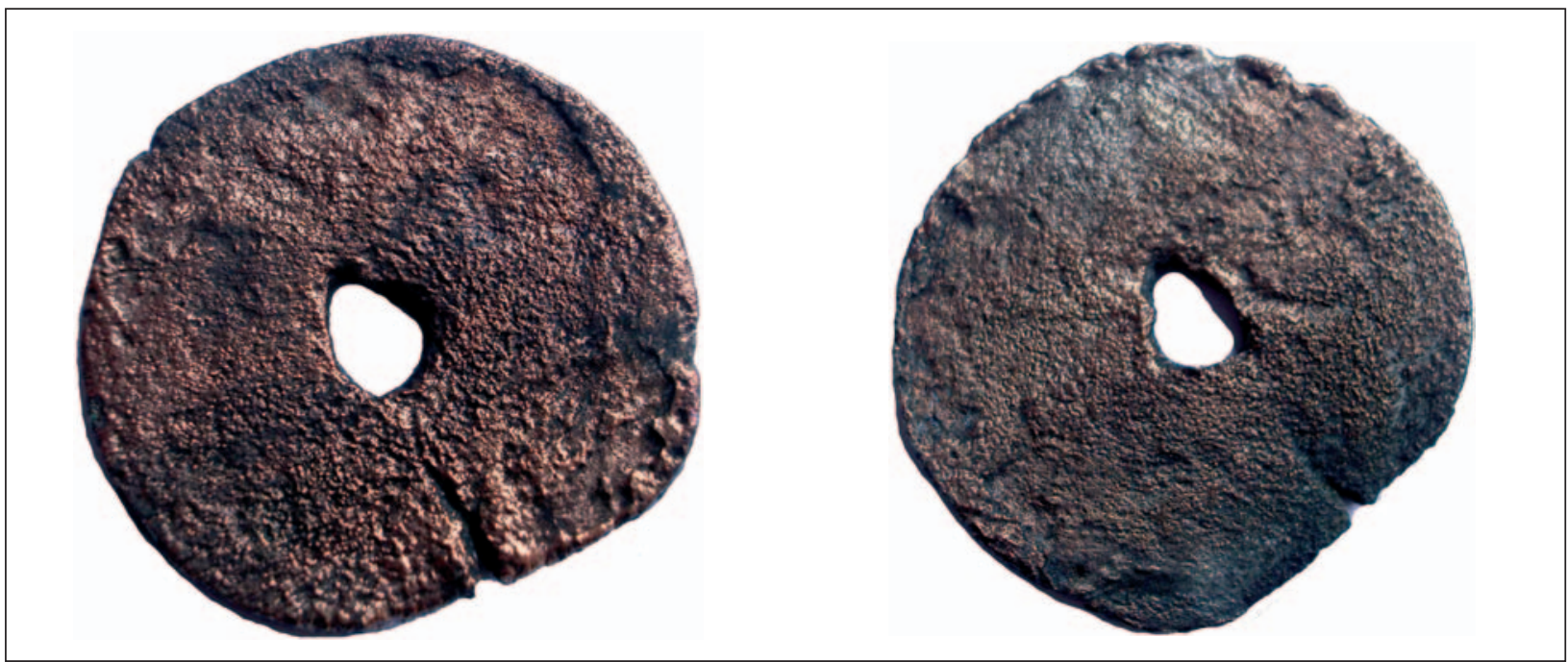

Figura 6. Moneda imperial frustra con orificio central procedente de la Ciudad de la Justicia (fotografía cortesía de F.J. Blanco).

2 Aunque en el estudio que Vaquerizo $(2010,159)$ ha realizado recientemente sobre la necrópolis romana de Cádiz hace referencia a la existencia del rito de óbolo de Caronte, por la moneda encontrada en la tumba 16 de la zona de la necrópolis excavada en la calle Ciudad de Santander esquina a la
Avda. de Andalucía. Queremos aclarar que no consta ni en la memoria de la excavación ni en lo publicado en el Anuario Arqueológico de Andalucía que la pieza se localizara en la boca, sino que aparece entre los elementos del ajuar (Perdigones, Muñoz y Troya, 1988: 44). 
misma intervención arqueológica (fig. 7). Se trata de una fosa simple sin cubierta, en cuyo interior se deposito el cadáver de un individuo infantil, en posición decúbito supino con los brazos semiflexionados y las piernas extendidas. Junto al cadáver se hallaron dos anillos de pasta vítrea, y a los pies la moneda con orificio central, sumamente desgastada por lo que tan sólo se puede indicar que se trata de un ejemplar de los siglos I o II d.C. La disposición de la perforación no parece que se realizara para ser suspendida, sino más bien con el deseo de inutilizar la acuñación por sí se producía la tan temida violatio sepulcrales.

Parece pues que aunque el tipo de numerario ya no es el emitido por la propia ciudad, el uso y significado de éste en relación al difunto ha variado muy poco con respecto a la fase tardo-púnica. Así, y aunque es cierto que en general en el mundo antiguo la moneda tuvo un papel especial, gracias a los elementos que hacen de ella una candidata perfecta para ser utilizada como amuleto, en Gades parece tratarse de una clara pervivencia de las costumbres rituales púnicas, como tantas otras manifestaciones funerarias gaditanas.

Se hace evidente que a pesar de los avances en este tipo de investigación, nuestro conocimiento sobre la presencia de moneda en el mundo funerario gaditano continúa siendo limitado y fragmentario, por lo que continuamos revisando lo aparecido hasta el momento para poder elaborar un trabajo de síntesis que contribuya a su correcta interpretación, pues hasta ahora habitualmente se había recurrido a tópicos y a la extrapolación de datos de otras regiones o a la aplicación de informaciones de tipo genérico aportadas por las fuentes literarias, caso del conocido "óbolo de Caronte" (Ritoré, 2011), sin mirar a lo que el propio registro arqueológico nos muestra; cuando

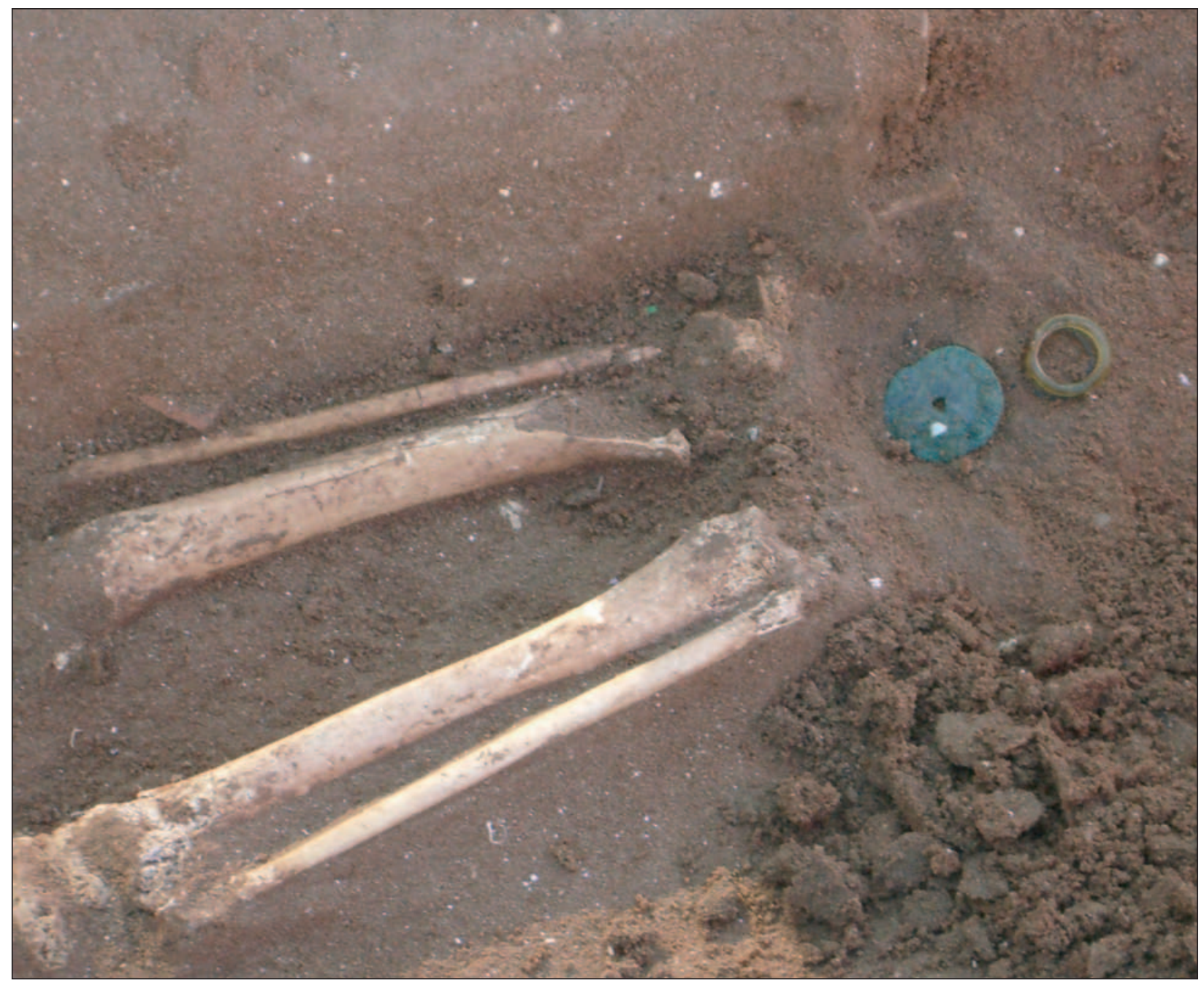

Figura 7. Detalle de la disposición de la moneda perforada encontrada en la inhumación $n^{\circ} 10$ de la Ciudad de la Justicia (fotografía cortesía de F.J. Blanco). 
éste es sumamente rico y variado, como hemos intentado mostrar en este trabajo, y que permite ir caracterizando este interesante ámbito funerario, en el que perviven numerosas tradiciones púnicas, como documentan, entre otros, los hallazgos monetarios en las tumbas, no convenientemente analizados hasta ahora. Estos demuestran que se trata de una costumbre que comienza en el siglo III a.C., cuando la ciudad comenzó a contar con su propio numerario y que continua hasta al menos mediados del siglo I d.C, momento en el que comienza a ser sustituido por el numerario romano, aunque se mantendrá en numerosas ocasiones el mismo uso y significado que en la época púnica, como manifiesta la continuidad en la disposición sobre determinadas partes del cuerpo del difunto, y no incorporándose el conocido rito del óbolo de Caronte, que ya se había adoptado en otras necrópolis hispanas.

\section{BIBLIOGRAFÍA}

ALFARO ASINS, C. (1988), Las monedas de Gadir / Gades, Madrid.

- (1993), 'Uso no monetal de algunas monedas púnicas de la península Ibérica', Revista Italiana di Numismatica e Scienze afini, XCV, 261-76.

ARÉVALO GONZÁLEZ, A. (2006): "El valor simbólico y el uso cultural de la moneda en la costa gaditana", Moneda, cultes i ritus, Barcelona, 7598

- (2009): "La moneda en el ámbito funerario y ritual de la necrópolis de Cádiz: el hallazgo de pozos", en ARÉVALO GONZÁLEZ, A. (ed.), XIII Congreso Nacional de Numismática. Moneda y Arqueología, Cádiz, 197-216.

- (2010a): "Monedas para el más allá. Un primer acercamiento desde la necrópolis de Cádiz", en NIVEAU, A. M ${ }^{\mathrm{a}}$; GÓMEZ, V. (Coords.), Las necrópolis de Cádiz. Apuntes de arqueología gaditana en homenaje a J. F. Sibón Olano, Diputación de Cádiz y Universidad de Cádiz, Cádiz., 507-528.

- (2010b): "Interpretación y posibles uso de la moneda en la necrópolis de Gadir", Mainake, XXXII (I), 15-36

- (2011), 'La moneda en el mundo funerario-ritual de Gadir-Gades', Actas del XIV Congreso Internacional de Numismática (Glasgow, 2009), 1229-1239

BELEN, M. et alii (1986): "Rituals funeraris a la Necrópolis romana", Cota Zero, 2, 53-61.
BELTRÁN HEREDIA, J. (2007): "La via sepulcral romana de la plaça de la villa de Madrid", Quaderns d'Arqueologia i Historia de la ciutat de Barcelona. Documents Museu d'Histoira de Barcelona 3, 6-124.

BENDALA, M. (1991a): "Incineration et inhumation dans l'Occidente aux trois premiers siècles de notre ère, le Sud de l' Espagne". Incinerations et inhumations dans l'Occident Romain sur trois premiers siècles de notre ère, Toulouse, 77-90.

- (1991b): "El banquete funerario en el mediodía hispano: una observación", Gerión. Anejos III Alimenta. Estudios en Homenaje al Dr. Michael Ponsich, Madrid, 181-186.

- (1995): "Necrópolis y ritual funerario en la Hispania Altoimperial”, en FÁBREGAS, R., PÉREZ, F., HERNÁNDEZ, C. (eds.), Arqueoloxía da Morte na Peninsula Ibérica desde as orixes ata o medievo, Santiago de Compostela, 277-290.

- (2002): "Perduraciones y romanización a la luz de la arqueología funeraria: notas para una discusión", Archivo Español de Arqueología 75, 137-158.

BLANCO JIMÉNEZ, F.J. (1988a): "Estudio numismático de la necrópolis romana de Cádiz", en Anuario Arqueológico de Andalucía'86, II, Sevilla, 531-539.

- (1988b): "Las monedas de la necrópolis romana de Cádiz de época imperial", en Congreso Internacional El Estrecho de Gibraltar, Madrid, vol. I, 1033-1045.

- (1998): Memoria de las excavaciones efectuadas en el solar ubicado en la Plaza de Asdrúbal esquina con el Paseo Marítimo durante 1997/98, Memoria inédita depositada en la Delegación Provincial de Cultura de Cádiz, Cádiz.

- (2009): "Hallazgo inédito de un tesorillo de monedas en el interior de una urna cineraria romana (antiguo cine Brunete. Cádiz)", en ARÉVALO GONZÁLEZ, A. (ed.), XIII Congreso Nacional de Numismática. Moneda y Arqueología, Cádiz, 217-244.

BUSTAMANTE ÁLVAREZ, M. (2008): "Cerámica y poder: el papel de la terra sigillata en la política romana", Anales de Arqueología Cordobesa, 19, 83-200.

- (2010): El Comercio de Terra Sigillata altoimperial en el Circulo del Estrecho, Oxford, British Archaeological Reports International Series.

CANTILENA, R. (1995): "Un obolo per Caronte? Caronte. Un obolo per l'aldila", La Parola del Pasato I, 165-177. 
CORZO, R. (1992): “Topografía y ritual en la necrópolis de Cádiz”, SPAL, 1, 263-292.

GOZALBES, M. (1997): "Los hallazgos numismáticos de una necrópolis de Valentia (C/Virgen de la Misericordia)", Anales de Arqueología Cordobesa 8, 197-212.

LÓPEZ DE LA ORDEN, Ma D. (2001): De Epigraphia Gaditana, Cádiz.

- (1997): "Dos nuevas inscripciones funerarias de la necrópolis romana gaditana", Gades, 22: 255 258.

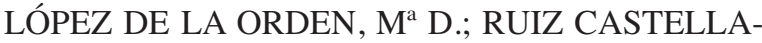
NOS, A. (1995): Nuevas inscripciones latinas del Museo de Cádiz, Cádiz.

LÓPEZ ELISO, J.M. (2009): "La moneda en la necrópolis de Gades entre los siglos III y V d.C.", en ARÉVALO GONZÁLEZ, A. (ed.), XIII Congreso Nacional de Numismática. Moneda y Arqueología, Cádiz, 537-582.

LÓPEZ ROSENDO, E. (2010):“Urnas pintadas de tradición prerromana en la necrópolis de Cádiz”, en NIVEAU, A. Ma; GÓMEZ, V. (Coords.), Las necrópolis de Cádiz. Apuntes de arqueología gaditana en homenaje a J. F. Sibón Olano, Cádiz., 145-177.

LÓPEZ RUIZ, U. y TINOCO RUIZ, A. (2011) "Hallazgo de un conjunto monetal de Gadir en la necrópolis feno-púnica de los Cuarteles de Varela, Cádiz (España)", Actas del XIV Congreso Internacional de Numismática (Glasgow, 2009).

MIRANDA, J. y PINEDA, P. (1999): Edificio "Puerto Varela” Avda. Andalucía, s/n (Cádiz). Intervención arqueológica de urgencia, Cádiz, Memoria inédita depositada en la Delegación Provincial de Cádiz.

MORALES, C.M. (2006): "La necrópolis de Gades: la complejidad de su ubicación”, en AAVV, Dossier. Arqueología de la Muerte. Revista de Historia Ubi sunt? 20, 32-41.

MUÑOZ VICENTE, A. (1987): "Avance Sobre el estudio de los ungüentarios helenísticos de Cádiz 1986", Anuario Arqueológico de Andalucía 1986II, 520-525.

Niveau De Villedary Y Mariñas, A. M. (2001):’Pozos púnicos en la necrópolis de Cádiz. Evidencias de prácticas rituales funerarias", Revista di Studi Fenici, XXIX-2, 233-252.

- (2003):"El uso ritual de la vajilla cerámica en la necrópolis púnica de Cádiz", Archivo Español de Arqueología, 76, 3-30.
- (2004): "La cerámica púnico-gaditana del siglo III a.C. El uso de la vajilla en el ámbito funerario y ritual de la necrópolis", en El Mundo Púnico. Religión, anrtopología y cultura material. Actas del II Congreso Internacional del Mundo Púnico, Murcia, 267-297.

- (2006): "Banquetes rituales en la necrópolis púnica de Gadir", Gerión 24, Madrid, 35-64.

- (2009): Ofrendas, banquetes y libaciones. El ritual funerario en la necrópolis púnica de Cádiz, Spal Monografías XII, Sevilla.

NIVEAU, A. Ma y GÓMEZ, V. (2010), “Captación y uso del agua en contextos funerarios y rituales. Estructuras hidráulicas en la necrópolis de Cádiz (Siglos III a.C. - I d.C.)", en Aquam Perducendam Curavit. Captación, uso y administración del agua en las ciudades de la Bética y en el Occidente romano, Cádiz, 511-532.

PERDIGONES, L.; MUÑOZ, A.; MARCOS, A. (1988): "Excavaciones de Urgencia en un solar de la Avda. Andalucía esquina plaza de Asdrúbal (Cádiz)", Anuario Arqueológico de Andalucía. 1986, Tomo III, Sevilla, 41-44

PERDIGONES, L.; MUÑOZ, A.; TROYA, A. (1988): "Excavaciones de urgencia en el solar de la calle Ciudad de Santander esquina Avda. Andalucía (Cádiz)", Anuario Arqueológico de Andalucía. 1985, Tomo III, Sevilla

PERDIGONES, L.; GORDILLO, A. Y BLANCO, F.J.. (1988): "Excavación en el solar de la calle General Ricardos n ${ }^{\circ}$ 5-7”, Anuario Arqueológico de Andalucía 1986, Tomo III, Sevilla, pp. 55-60.

RITORÉ PONCE, J. (2011): "El «óbolo de Caronte»: estado de la cuestión y relectura de fuentes", Mites, ofrendes funeràries i monedes, Barcelona

RUIZ GIL, J.A. (2006): "Morir en Gadir: un proyecto de investigación necesario", en AAVV, Dossier. Arqueología de la Muerte. Revista de Historia Ubi sunt? 20, 42-47.

RUIZ OSUNA, A. (2007): La monumentalización de los espacios funerarios en Colonia Patricia Corduba (Ss. I a.C. - II d.C.), Arqueología Cordobesa 16, Córdoba

- (2010): Colonia Patricia, centro difusor de modelos. Topografía y monumentalización funerarias en Baetica, Córdoba.

SÁEZ GÓMEZ, M. A. (1993): "Informe sobre las excavaciones de urgencia realizadas en el solar $\mathrm{n}^{\circ}$ 5 de la C/ Juan Ramón Jiménez, en Cádiz", Anuario Arqueológico de Andalucía 1991, Tomo III, Sevilla, 11-16 
Sibón Olano, F.J. (2001): Memoria preliminar de los resultados obtenidos de la excavación realizada en la Avda. Amilcar Barca. Secretaría General de la Seguridad social de Cádiz (junio-Julio 2001), Memoria inédita depositada en la Delegación Provincial de Cultura de Cádiz, Cádiz.

SIBÓN OLANO, J.F. et al. (2007): Memoria final de las excavaciones arqueológicas del Palacio de la Justicia. Cádiz 2004-05, Cádiz, Memoria inédita depositada en la Delegación de Cultura de Cádiz.

SIBÓN OLANO, J.F., GÓMEZ FERNÁNDEZ, V., NIVEAU DE VILLEDARY, A. (2010): "Intervención arqueológica de urgencia en el solar de la futura "Ciudad de la Justicia" (Cádiz)", Anuario Arqueológico de Andalucía 2004, 148158.
VALLEJO, J.I. y NIVEAU DE VILLEDARY, A. (1999): "Investigación y gestión de la arqueología urbana de Cádiz", XXV Congreso Nacional de Arqueología, Valencia, 348-351.

VAQUERIZO GIL, D. (2001): “Formas arquitectónicas funerarias de carácter monumental en Colonia Patricia Corduba", Archivo Español de Arqueología, 74, 131-160

- (2010a): Necrópolis urbanas de Baetica, Tarragona.

- (2010b): "Espacio y usos funerarios en el Gades romano; ¿Un lujo sacrificable?”, en NIVEAU DE VILLEDARY, A. y GÓMEZ FERNÁNDEZ, V. (coords.), Las necrópolis de Cádiz. Apuntes de arqueología gaditana en homenaje a J.F. Sibón Olano, Cádiz, 341-385. 